Operation.-A clinical diagnosis of fibroma was made, my opinion being that it was bi-lobed and that it had its origin on the right side of the vault close to the right choana, all of which proved to be correct. General anesthesia in such a case is practically impossible. Respiratory arrest is synchronous with unconsciousness. Dr. John W' Boyce very kindly infiltrated an area over the trachea, which enabled me to open the trachea in a few minutes absolutely without pain. This was remarkable in a frail boy, who was watching our every move. ment. Chloroform was now skillfully administered through the tracheal wound by Dr. W. H. Strang. The right external carotid artery was ligated between the lingual and the superior thyroid arteries to forestall hemorrhage. A small probe, in whose point a small eye had been drilled, was threaded with braided silk and passed backward through the right nasal chamber. It was insinuated between the growth and the tightly stretched velum, through which it could be felt as it worked backward. When the eye point of the probe reached the free margin of the velum, the silk was caught with forceps and drawn out the mouth for a convenient length and the probe was withdrawn from the nose. The bight of a length of snare wire was tied to the nasal end of the silk, by means of which the wire loop was drawn back through the nose until it reached the pharynx. The loop was then insinuated around the presenting portions of the growth and worked upward by traction on the ends projecting from the nose. When the loop was felt to be taut around the base of the growth, these projecting wire ends were threaded through the straight canula of a Peters tonsil snare by my assistant, Dr. Ellen J. Patterson. Closing the snare handles, the growth was cut through at one stroke. The severed tumor was then delivered with strong forceps, without lacerating the palate, though this seemed imminent, owing to the tight fit of the growth.

The bleeding was about as much as from an adenoidectomy; nothing like the welling up after the extirpation of a fibroma Anterior and posterior plugs were placed and the tracheal canula which had been inserted to facilitate anesthesia was removed as soon as the boy came out sufficiently. The plugs were allowed to remain forty-eight hours. No bleeding followed their removal.

The temperature rose to $101 \mathrm{~F}$., but returned in two days to normal. The carotid wound healed promptly. The boy was out of bed on the third day, and was discharged well at the end of the week. No sign of pulsation was yet perceptible at the temporal artery two weeks later.

The right upper maxilla had undergone a pressure atrophy which had almost obliterated the antrum. There was no cartilage in the septum, probably also the result of the same process, and the nasopharyngeal cavity was enormous. The growth, which weighed 1,270 grains, was found by Dr. Ralph Duffey to be a pure fibroma.

When one looks over the appalling list of deaths on the table from hemorrhage in the removal of fibromata and over the list of preliminary operations, temporary and permanent jaw resections, etc., the contrast here recorded seems to furnish food for thought. I have ligated the external carotid artery thirty-four times without in any case an untoward result. Eight of these ligations have been preliminary to the extirpation of nasopharyngeal fibromata, and in no instance has the bleeding been serious. The greatness of the contrast can be realized only by one who has seen the blood well up out of the mouth like water out of a drinking fountain. External carotid ligation is a guarantee against hemorrhage, shock and collapse. Not only does it prevent loss of blood, but by diverting a greater quantity of blood into the internal carotid it increases intracerebral blood pressure. Whether this agrees with the physiologists' dynamics of blood pressure or not I do not know, but clinically I have seen throbbing headache and also insomnia of a few days' duration follow external carotid ligation, and I have seen no shock in eight cases of extirpation of nasopharyngeal fibromata, cases similar to ones in which death occurred from hemorrhage and collapse. In my opinion, these observations point to increased intracerebral blood pressure after the ligation. The influence of local anemia in the prevention of recurrence is, of course, an additional advantage, especially in cases of double ligation, or, better still, exsection.

I do not consider an operation for true fibroma of the nasopharynx justifiable without preliminary ligation of one or both external carotid arteries. If the side from which the growth springs can not be determined, ligation of both external carotids is indicated, preferably with an interval of three or four days, during which the tracheal wound may be kept from healing by packing with gauze wrung out of mercuric bichlorid solution, no tube being worn and no air being permitted to pass through the wound. From this there is no danger of pneumonia. Nor do I consider it justifiable to administer a general anesthetic until after the trachea has been opened, if the growth be large enough to press the velum forward on to the tongue. I do not say that neglect of these precautions means death, but I claim that the mortality of these operations can be thus reduced practically to naught. Hemorrhage, dyspnea and chloroform act synergistically in the induction of collapse. Let us forestall hemorrhage by external carotid ligation and dyspnea by tracheotomy (under local anesthesia) so that we may give our chloroform in comparative safety.

\section{METHOD OF WASHING SMALL PIECES OF TISSUE.}

\section{GUTHRIE MCCONNELI, M.D. ST. LOUIS.}

I have devised a method of washing small bits of tissue which have been hardened in Zenker's or similar fluids, and which does away with the difficulties usually encountered in that proceeding.

As shown in the accompanying illustration, a piece of fine. meshed copper wire netting is rolled into a cylinder and stuck

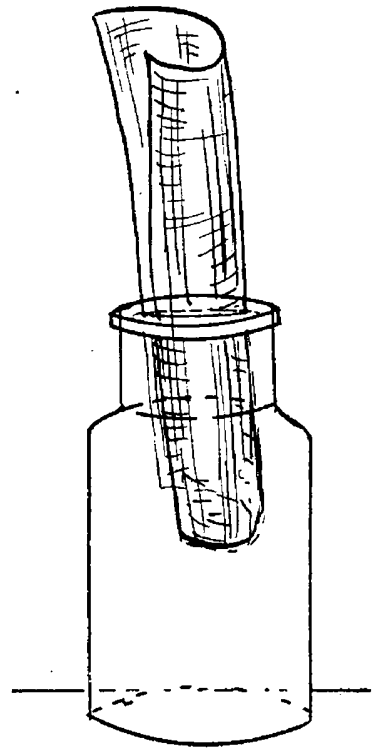

well down into a bottle. The bits of tissue are put in this and the water is turned on; all danger of losing the specimen is obviated as the water can not rise to any degree above the mouth of the bottle.

Until I happened to think of this method I had to devise rather elaborate or cumbersome ways of accomplishing the desired end. 